\title{
Clinical Efficiency Analysis of Share Decision Making in the Atrial Fibrillation Patients
}

\author{
Hao-Min Cheng ${ }^{1}$, Hong- Di Chang ${ }^{2}$, Hsin-Chan Huang ${ }^{2}$, Hsiao-Fen Hsu ${ }^{2}$, Chih-Yi Lee ${ }^{2}$, Mei-Jyh Sheu ${ }^{2}$ \& \\ Hsiao-hui Chiu ${ }^{2,3}$ \\ ${ }^{1}$ Division of Cardiology, Taipei Veterans General Hospital, Taipei, Taiwan \\ ${ }^{2}$ Taipei Veterans General Hospital, Taipei, Taiwan \\ ${ }^{3}$ Department of Nursing, National Taipei University of Nursing and Health Sciences, Taipei, Taiwan \\ Correspondence: Hsiao-hui Chiu, No.201, Sec. 2, Shipai Rd., Beitou District, Taipei City, 11217, Taiwan. Tel: \\ 886-2-2871-2121.
}

Received: June 7, 2020

Accepted: July 25, 2020

Online Published: July 30, 2020

doi:10.20849/ijsn.v5i3.765

URL: https://doi.org/10.20849/ijsn.v5i3.765

\begin{abstract}
Background: Atrial Fibrillation (AF) prevalence rate is about $2 \%-3 \%$ worldwide. The risk of stroke in patients with AF is $4-5$ times than normal. It's important to take oral anticoagulant therapies to prevent stroke.

Aims: The purpose of this study was to estimate whether share decision making (SDM) could lower the anxiety and improve the intension of medical decision or not.

Methods: This was one-group pretest-posttest study design. The study contained 21 patients who had hospitalized following diagnosis and treatment of AF pectoris in Cardiology in the Veterans General Hospital. After using health education, patient filled out the questionnaire. TREND guideline has been adhered to in the reporting of this study.

Results: The anxiety level decrease after the SDM from 2.8 to 1.2 points ( $p$-value<0.05) and the rate of the intension to choose medication increase from $57 \%$ to $76 \%$. The promote factors are "After patient understand the disease and treatment, they are ready for consultation (83\%)". Medical staff believes that the relevant factors of "System-related difficulties" are "Insufficient time to talk with patient (45\%)".

Conclusion: Both medical staff and patients have positive feedback and statistically significant differences in affecting the patient's medical willingness and reducing patient anxiety in SDM. It is important to help patients to think and evaluate carefully through SDM and determine the most appropriate treatment.
\end{abstract}

Keywords: decision making, atrial fibrillation, anticoagulants

\section{Introduction}

Atrial fibrillation (AF) is a common arrhythmia, and its prevalence is about $2 \%-3 \%$ worldwide. Analysis of National Health Insurance (NHI) data in Taiwan has showed that the patients suffered from atrial fibrillation account for about $1-2 \%$ of the total population, which is estimated to be about 230,000 patients with atrial fibrillation. Atrial fibrillation is a major risk factor of cardioembolic stroke. According to previous studies, about 1 in 5 strokes are caused by atrial fibrillation, and the risk of stroke in patients with atrial fibrillation is $4-5$ times than normal. According to the data of Taiwan stroke registry system, $16.5 \%$ patients with ischemic stroke have suffered from atrial fibrillation, and about $5 \sim 7 \%$ patients are over 65 years old, and the incidence rate is as high as $10 \%$ in the patients over 75 years old (Chiang et al., 2016; Chan et al., 2018; Information network of atrial fibrillation health of the Medical Association of the Republic of China,2020). Atrial fibrillation is the rapid and irregular beating of the atrium. Once it occurs, because the atrium does not contract effectively, the blood in the atrium will be in a state of poor flow, and the blood will easily condense into a thrombus. Once the thrombus flows with the blood flow to the brain, it will block the blood vessels in the brain and cause a stroke. The prognosis will be poor and the recurrence rate will be high. According to CHA2DS2-VASc score for stork risk stratification, the assessment score is ranged from 0 to 9 points. The higher the score, the greater the risk. Based on the empirical researches, for every 1,000 people, the stroke rate of 0 points is 12 people, and a score of 9 is as high as 107 people. The assessed risk factors include " Congestive heart failure (1 score) "," Hypertension (1 
score)", "age $\geq 75 y$ ( 2 score)", "Diabetes mellitus (1 score)", "Stroke / Transient ischemic attack (2 score)", "Vascular disease (1 score)", "Age 65-74y (1 score)", and "Sex category (1 score)" (Chao et al., 2016). Based on the recommendation of 2012 focused update of the ESC Guidelines for the management of atrial fibrillation and 2014 ACC/AHA Guideline for the Management of Patients With Atrial Fibrillation, the patients with CHA2DS2-VASc score of 2 or more should take oral anticoagulant therapies to prevent stroke, unless contraindications existing (January et al., 2014). Warfarin, a traditional anticoagulant drug, can reduce the rate of stroke by about $64 \%$. However, warfarin in addition to interacting with many foods and drugs, the patients who take this drug often need to withdraw blood to monitor drug concentrations in blood, and increase the risk of cerebral hemorrhage. Therefore, the public acceptance is not high, and physicians have many concerns when prescribing anticoagulant drugs. Currently, a new oral anticoagulant drug-non-vitamin $\mathrm{K}$ antagonist oral anticoagulants (NOAC) has been approved by USFDA and TFDA. It can be used for prevention of stroke in patients with atrial fibrillation. Compared to warfarin, it is convenient to use and does not need to monitor the concentration of the drug, and the risk of cerebral hemorrhage are also greatly reduced. In previous empirical studies, it was found that, in the patients taking NOAC, about 23-30 patients had strokes per 1000 people, and 15-21 people had severe bleeding. In the patients taking Warfarin, about 35 patients had strokes per 1,000 people, and 33 people had severe bleeding. But stroke prevention effects of both NOAC and Warfarin are similar (Chan et al., 2018).

Shared decision making (SDM) is a process in which clinicians and patients work together to select tests, treatments, management or support packages, based on clinical evidence and the patient has informed preferences. It involves the provision of evidence-based information about options, outcomes and uncertainties, together with decision support counseling and a system for recording and implementing patients' informed preferences (Angela, 2014). The International Alliance of Patients' Organizations (IAOP) who emphasis patient-centered healthcare as care that is aimed at addressing the needs and preferences of patients. There are five principles which are foundational to the achievement of patient-centered healthcare: respect, choice, policy, access and support, information. The idea of SDM is clearly evident (Truglio-Londrigan, Slyer, Singleton, \& Worral, 2012).SDM includes decision 3 [E]: 1) Best Research Evidence); 2) Clinical Experts Experience; 3) Patients' Value and Expectation) (Wang, 2016). Tonelli (Tonelli \& Sullivan, 2019) SDM have two essential elements:1) focused on treatment choices; 2)the clinician is primarily responsible for providing options while the patient contributes values and preferences. SDM is collaboration in all aspects of care, clinicians needing to fully engage with the patient's experience. Patient Decision Aid (PDA) take a variety of forms, spanning everything from simple one-page sheets outlining the choices, through more detailed leaflets or computer programmers, to DVDs or interactive websites that include filmed interviews with patients and professionals, enabling the viewer to delve into as much or as little detail as they want (Angela , 2014). Hargraves (Hargraves et al., 2019) SDM are needed in situations of 1) Uncertain harms and benefits; 2) Intra or interpersonal conflict; 3) Intellectual, practical, and emotional incoherence; 4) Existential transition. While SDM isn't considered to be related to clinical work, clinicians won't be willing to adopt it. Chang (2019) found that after used SDM anxiety levels were reduced from $57.1 \%$ to $28.6 \%$ and affected treatment choices, improved health awareness and facilitate communication with the doctor. Chou (2017) found that the most satisfying items were "SDM help understand the things that are most important in the face of various medical options" and "SDM to help make the most appropriate medical choices". Used SDM the level of anxiety significantly reduced $(2.7 \pm 0.7 \mathrm{vs} .2 .2 \pm 0.5, \mathrm{p}=<0.001)$. Stacey (2014) found SDM increase patients knowledge. The success factors included the previous knowledge of patients, the impact on the quality of life, and more difficult to discuss in a painful situation (Joseph-Williams et al., 2019). Ryan (2014) found the rate of performing surgery through discussion could reduce by $20 \%$. Shen (2019) found increased willingness of treating spinal fractures from $68.1 \%$ to $97.9 \%$, with an increase of $29.8 \%$, which indicated that the use of SDM had the benefit of increasing the willingness to accept treatment.

The purposes of this study were whether medical staff's recognition of that SDM can help patients, factors of promotion and obstacle. Did the anxiety level decrease after used SDM and PDA?

\section{Method}

\subsection{Research Design}

This was one-group pretest-posttest study design. Scholars and experts of the SDM Promotion - cardiology Pectoris Group from the Ministry of Health and Welfare, who used empirical methods to complete the questionnaire of " I have atrial fibrillation and should I take anticoagulants to prevent stroke?". It includes introduction, introduction of illness or health agenda, introduction of medical options, the method you currently prefer, the comparison of options, the options you care about and the degree of concern, understanding of the message, confirming treatment and relative information. The medical staff would evaluated by intelligibility and 
professional suitability.

The questionnaire included: 1) Patients: Used the public medical aids opinion questionnaire that was developed by the Taiwan Ministry of Health and Welfare, included 10 questions about the efforts made by medical staff and 3 questions about medical decision-making intension. 2) Medical staff: Used the public medical aids opinion questionnaire that was developed by the Taiwan Ministry of Health and Welfare. Included 11 questions for recognition of how the SDM helps patients, 13 questions for promoting factors, 17 questions for obstacle factors (6 questions for system factors, 11 questions for patient factors). Four nurses of cardiology are responsible for conducting a consensus meeting under the guidance and supervision of cardiology physician to confirm the process and methods and to practice the use of assistive tool descriptions. In the end, the opinions of four colleagues had to be consisted unanimous.

\subsection{Participants}

The patients participated in this study, outpatients of cardiology in a Venterans General Hospital from July 1 to Sep 30, 2019. Included criteria: 1) Patients who had been diagnosed with atrial fibrillation. 2) Doctors recommend that patients take oral anticoagulants. Excluded criteria: 1) patients who had not diagnosed with atrial fibrillation. 2) Unable to communicate in Taiwanese. 3) Unwilling to accept health education guidance and questionnaires.

\subsection{Data Collection}

After physicians gave oral instructions, they agreed to receive medical guidance and complete questionnaires. First, posting the recruitment advertisements in the waiting area of the cardiology clinic and the cardiologist will explain the purpose and process of study to the patient who is suitable for the study. With the patient's verbal consent, the patient will be transferred to a quiet and private health education space. Secondly, one-on-one professional consultation with decision-making aid tool will be held for about 20-30 minutes, and complete the questionnaire of "I have atrial fibrillation and should I take anticoagulants to prevent stroke?" In addition, medical staff will also complete the questionnaire after seeking consent. This study was SDM promotion plan of Ministry of Health and Welfare in 2018. Enrollment of this study was performed after the study was reviewed and approved by the Institutional Review Board of LCGMH (IRB No. 201900783 B0).

\subsection{Data Analysis}

The data were keyed in using Excel with an anonymized encoding process. The statistical software SPSS 20.0 (IBM SPSS Inc. Chicago Illinois) frequency, percentage, Wilcoxon rank sum test, Chi-square test. The significance level was set at $\alpha=0.05$.

\subsection{Validity and Reliability}

The measure tools included:

(1) Patients: Using the public medical aids opinion questionnaire that was developed by the Taiwan Ministry of Health and Welfare, including 10 questions about the efforts made by medical staff and 3 questions about medical decision-making intension.

(2) Medical staff: Using the public medical aids opinion questionnaire that was developed by the Taiwan Ministry of Health and Welfare. Including 11 questions for recognition of how the SDM helps patients, 13 questions for promoting factors, 17 questions for obstacle factors (6 questions for system factors, 11 questions for patient factors).

(3) Scholars and experts of the SDM Promotion -Angina Pectoris Group from the Ministry of Health and Welfare, who use empirical methods to compile the questionnaire of " I have atrial fibrillation and should I take anticoagulants to prevent stroke?". It includes introduction, introduction of illness or health agenda, introduction of medical options, the method you currently prefer, the comparison of options, the options you care about and the degree of concern, understanding of the message, confirming treatment and relative information. The medical staff will be evaluated by intelligibility and professional suitability. If 4 points as total score, the average score of each paragraph is 3.72 , which resulted $93 \%$ and the average score is $85 \%$ in terms of help and practicality. The public will be evaluated by the intelligibility of each paragraph. If 4 points as total score, the average score of each paragraph is 3.3, and score percentage is $82 \%$.

(4) Consistency of researchers: Four clinical staffs of cardiology are responsible for conducting a consensus meeting under the guidance and supervision of cardiology physician to confirm the process and methods and to practice the use of assistive tool descriptions. In the end, the opinions of four colleagues have to be consisted unanimous. 


\section{Results}

\subsection{Sample Characteristics}

The number of patients that used SDM was 21 . There were $52.4 \%$ people were male, $52.4 \%$ were $60-79$ years old, most people's education level is college (47.6\%). Total 29 medical staff was included in this survey, $75.9 \%$ of medical staff was nurses and the mean age of work was $1-5$ years $(37.9 \%)$. (Table 1) The top of CHA2DS2-VASC score were 2 points (23.8\%), 3 points (19.0\%), 4 points (14.3\%). "Hypertension" accounted $57.1 \%$, "the others age" $\geq 75 y$, "vascular disease" and "female "were $23.8 \%$.

Table 1. Demographic information

\begin{tabular}{|c|c|c|c|}
\hline \multicolumn{2}{|l|}{ Variables } & No. & $\%$ \\
\hline \multicolumn{4}{|l|}{ Patient $(\mathrm{n}=21)$} \\
\hline \multirow[t]{2}{*}{ Gender } & Men & 11 & 52.4 \\
\hline & Women & 10 & 47.6 \\
\hline \multirow[t]{3}{*}{ Age } & $40-49$ years old & 5 & 23.8 \\
\hline & $50-59$ years old & 5 & 23.8 \\
\hline & $60-79$ years old & 11 & 52.4 \\
\hline \multirow[t]{3}{*}{ Education } & Senior high school & 7 & 33.3 \\
\hline & College & 10 & 47.6 \\
\hline & Master degree & 4 & 19.1 \\
\hline \multirow[t]{4}{*}{ Attendant } & Alone & 10 & 47.6 \\
\hline & Spouse & 2 & 9.5 \\
\hline & Offspring and their spouses & 5 & 23.8 \\
\hline & Other relatives & 4 & 19.0 \\
\hline \multicolumn{4}{|c|}{ Medical staff $(\mathrm{n}=29)$} \\
\hline \multirow[t]{2}{*}{ Occupation } & Doctor & 7 & 24.1 \\
\hline & Nurse & 22 & 75.9 \\
\hline \multirow[t]{5}{*}{ Job tenure(year) } & $1-5$ & 11 & 37.9 \\
\hline & $6-10$ & 6 & 20.7 \\
\hline & $11-15$ & 3 & 10.3 \\
\hline & $16-20$ & 3 & 10.3 \\
\hline & Above 21 & 6 & 20.7 \\
\hline \multirow[t]{2}{*}{ Gender } & Men & 7 & 24.1 \\
\hline & Women & 22 & 75.9 \\
\hline
\end{tabular}

\subsection{The Impact for SDM on Decision-Making of Patient}

The $67 \%-71 \%$ patients recognize the efforts made by the medical staff, which is "a lot", which followed by "What is the level of effort of medical staff while they hear health problem that matters to you the most? (71\%)", "What is the level of effort of medical staff while they take things that matters to you in to consideration? (71\%)", "What is the level of effort of medical staff while they help you to realize your health problem? (67\%) which has only 5\% people choose" Few in questionnaire. It shows that medical staff should pay more attention to what patients care about when they select patients (Table 2). Before using SDM, 33\% of patients choose "unclear" and decrease $28 \%$ after using SDM. The rate of people who choose "Take medicine" increased $19 \%$, from 57\% to $76 \%$. The rate of people who choose "No medicine" increased 9\%, from 10\% to 19\%.The Chi-square test was used to analyze the patient decision sharing $(X 2=14.25, \mathrm{p}=.0065)$. The result shows that there is a statistically significant difference in the patient's decision after sharing the decision. Decision sharing does have a positive 
effect on patients (Table 3). The assistance of decision-making tool on patient can be rated from 1 to 5 points, with an average score of 4.0 points. "How much anxiety do you have while face current medical problems before using SDM?" scores 4.0 points. "How much anxiety do you have while face current medical problems after using SDM" is 2.8 points, which shows that the anxiety level reduced 1.2 points after health education. The anxiety level of patients before and after sharing decision was tested by Wilcoxon rank sum test (the $\mathrm{z}$ value was $2.78, \mathrm{p}=0.0027$ ), which means that the patient's level of anxiety statistically decreased after using SDM.

Table 2. Patient's recognition on effort of medical staff $(n=21)$

\begin{tabular}{|c|c|c|c|}
\hline Subject & $\begin{array}{l}\text { Few } \\
\mathrm{n}(\%)\end{array}$ & $\begin{array}{l}\text { Some } \\
\mathrm{n}(\%)\end{array}$ & $\begin{array}{l}\text { A lot } \\
\mathrm{n}(\%)\end{array}$ \\
\hline $\begin{array}{l}\text { What is the level of effort of medical staff while they help you to realize } \\
\text { your health problem? }\end{array}$ & 0 & $7(33)$ & $14(67)$ \\
\hline $\begin{array}{l}\text { What is the level of effort of medical staff while they hear health problem } \\
\text { that matters to you the most? }\end{array}$ & 0 & $6(29)$ & $15(71)$ \\
\hline $\begin{array}{l}\text { What is the level of effort of medical staff while they take things that } \\
\text { matters to you in to consideration? }\end{array}$ & $1(5)$ & $5(24)$ & $15(71)$ \\
\hline
\end{tabular}

Table 3. Comparison of patient before and after using SDM $(n=21)$

\begin{tabular}{lllll}
\hline Subject & Before SDM (\%) & After SDM (\%) & Difference (After- Before) & P-value \\
\hline Unclear & 33 & 5 & -28 & $0.0065^{*}$ \\
\hline Take medication & 57 & 76 & +19 & \\
\hline No medication & 10 & 19 & +9 & \\
\hline
\end{tabular}

\subsection{SDM Associated Factor of Promotion}

The top three promoting factors among medical staff for SDM implementation are "After patient understand the disease and treatment, they are ready for consultation (83\%)", "Improve doctor-patient relationship (66\%)", and "Improve doctor-patient communication efficiency (66\%)". The result shows that hard copy of SDM can improve doctor-patient communication efficiency and the doctor-patient relationship at the same time (Table 4).

Table 4. Facilitating factors for medical staff to promote SDM (multiple choice) $(n=29)$

\begin{tabular}{lll}
\hline Subject & $\%$ & Ranking \\
\hline After patient understand the disease and treatment, they are ready for consultation & 83 & 1 \\
\hline Improve doctor-patient relationship & 66 & 2 \\
\hline Improve doctor-patient communication efficiency & 66 & 2 \\
\hline Provide hard copy & 62 & 4 \\
\hline Patient-centered care & 48 & 5 \\
\hline Increase the participation of patient during medical care & 45 & 6 \\
\hline Patient has attendant during consultation & 41 & 7 \\
\hline Patient trust me & 41 & 7 \\
\hline Convenient decision aid tool is available & 38 & 9 \\
\hline Demand of national policy & 34 & 10 \\
\hline Wish to improve clinical care & 31 & 11 \\
\hline Wish to decrease cost of medical care & 21 & 12 \\
\hline Others & 3 \\
\hline
\end{tabular}




\subsection{Obstacle Factors for Pushing SDM}

Medical staff believes that the relevant factors of " System-related difficulties " are "Insufficient time to talk with patient" (45\%), "Patient takes family factors as prior consideration while choosing treatment (38\%)", and "Patient prefer treatment instead of consultation (31\%)." "Patient-related difficulties" are "Patient hesitate (69\%)", "Patient couldn't listen to the medical staff because of the worries (41\%)", "Patient does not understand the information I provide (34\%)". The traditional medical communication model mainly based on the professional opinions of physicians. However, due to changes in policies and implementations, patients need more time to learn and accept the new model of medical-patient sharing decision making. Besides, there is not enough time for discussion because of limited clinical time. It is common for patient to hesitate to make an immediate decision in clinical practice. The hard copy of decision-making tools allows the patient to bring it back to read, think and discuss with family members before the next visit. After discussing and asking key questions, it can help communication between doctors and patients, and then make decisions that can decrease the difficulty of medical staff in using SDM (Table 5).

Table 5. Obstacles to medical staff's promotion of SDM (Multiple Questions) (n=29)

\begin{tabular}{lll}
\hline Subject & $\%$ & Ranking \\
\hline System-related difficulties & & \\
\hline Insufficient time to talk with patient & 45 & 1 \\
\hline Patient takes family factors as prior consideration while choosing treatment & 38 & 2 \\
\hline Patient prefer treatment instead of consultation & 31 & 3 \\
\hline Others & 17 & 4 \\
\hline During the first consultation, I didn't have enough information to assist patients to & 14 & 5 \\
make medical decision & & \\
\hline I face problems while providing treatment for patient & 7 & 6 \\
\hline Patient-related difficulties & & \\
\hline Patient hesitate & 69 & 1 \\
\hline Patient couldn't listen to the medical staff because of the worries & 41 & 2 \\
\hline Patient don't understand the information I provide & 34 & 3 \\
\hline Patient has misunderstanding with the disease and treatment & 21 & 4 \\
\hline Patient has hard time to accept the fact that he has disease & 21 & 4 \\
\hline Can't discuss with patient because of too many information which patient brings & 17 & 6 \\
\hline Uncertain about the treatment which patient requires is benefit or not & 17 & 6 \\
\hline Patient didn't want to use SDM & 14 & 8 \\
\hline Patient wants to get involve with more treatment decision & 10 & 9 \\
\hline Patient refuses the treatment that I recommend & 10 & 10 \\
\hline Others & 3 & 11 \\
\hline
\end{tabular}

\section{Discussion}

The range age in this study were 30-79 years old, 52.4\% were 60-79 years. The age of incidence rate had the same trend with Information network of atrial fibrillation health of the Medical Association of the Republic of China(2020). 52.4\% of patients were men greater than female. The CHA2DS2-VASc score were 2 points (23.8\%). January (2014) suggested the patients with CHA2DS2-VASc score of 2 or more should take oral anticoagulant therapies to prevent stroke. This study found that "Take medicine" increased 19\%, from 57\% to $76 \%$. The rate of people who choose had the same trend with Ryan (2014) found the rate of reduced performing surgery by $20 \%$ through discussion with SDM. Shen (2019) increased willingness of treating spinal fractures from $68.1 \%$ to $97.9 \%$, with an increase of $29.8 \%$, which indicated that the use of SDM had the benefit of increasing the willingness to accept treatment. In addition, individual knowledge background was one of factors 
that influence the success of medical decision-making. If patient's emotion was stable, it is easy to discuss with them (Joseph-Williams et al.,2019). In this case, $66.7 \%$ of the patients had college or higher degree, and were easier to accept SDM during the angina pectoris stage. The CHA2DS2-VASc score were 2 points (23.8\%) stable condition.

While $83 \%$ of medical staffs agreed to promote SDM to "After patient understand the disease and treatment, they are ready for consultation", "Improve doctor-patient relationship (66\%)", and "Improve doctor-patient communication efficiency $(66 \%)$ "The result showed that the SDM can promote the efficiency of medical-patient communication and improve the relationship between doctors and patients. Chang (2019) surveyed the use of decision aids among medical staff. The highest score ( 4.8 points) appeared in "patients think about the pros and cons of each option", "patients can identify questions they want to ask medical staff" and "improve health recognition of patient". Moreover, the highest degree of recognition (4.8 points) in projects such as "promoting the relationship between doctors and patients" and "willing to share this decision-making process with other medical staff" indicated that PDA could increase medical service satisfaction. SDM is patient-centered healthcare as care that is aimed at addressing the needs and preferences of patients (Truglio-Londrigan, Slyer, Singleton, \& Worral, 2012).

Among the obstacle factors, "insufficient time to talk with patient "(45\%) believed to be the biggest obstacle in systemic problems. This study of SDM would take each patient 20-30 minutes to do SDM, which would shorten the clinical time in the outpatient department. The discussion time with patient was insufficient to reflect truly the dilemma of the clinical staff. Hargraves (Hargraves et al., 2019) While SDM isn't considered to be related to clinical work, clinicians won't be willing to adopt it. Tonelli (Tonelli \& Sullivan, 2019) SDM is collaboration in all aspects of clinical care. The clinician must know the patient well enough to be able to answer the patient's question "What would you do if you were me?" Therefor SDM does not require excessive time or effort on the part of clinicians or patients. Therefore, the hospital should recruit sufficient labor to promote the government's policy of SDM. Another 69\% of medical staff believed that "patient hesitate" is the biggest problem among patients. While traditional medical decision-making was based on professional knowledge of physician, SDM emphasized doctor-patient sharing decision-making that means patients should learn to choose and decided by themselves. Due to the change of medical decision model, the government should continue to introduce and educate the meaning and method of SDM. Medical staff and patients must learn and accept the new medical decision-making process.

\section{Conclusion}

SDM was the discussion with the latest empirical research and personal professional between patients and doctor. The process included participation of physician and patient, information that help patients explore and compare more treatment options, evaluating patient values and considerations, sharing information between doctors and patients, establishing common opinion and reaching a treatment decision. In this study, we found that both medical staff and patients had positive feedback and statistically significant differences in affecting the patient's medical willingness and reduced patient anxiety in SDM. However, the lack of discussion time and hesitation of patient were two biggest obstacles while promote SDM.

\section{Study Limitation and Recommendation}

The study limited the small sample size and single group. For further study, increase the number of sample size.

According to this study, we recommend that

(1)Because it takes about 20-30 minutes for each patient of SDM, gaining work force of health education is the future direction.

(2) SDM has received not only positive feedback and affirmation from patients but also sense of professional accomplishment from nursing colleagues who is in charge of health education. Because medical staff is busy with work, the cognition and acceptance still need to improve. The government still needs to promote SDM, stimulates and encourages the participation of medical institutions and continues to demonstrate the effectiveness of promotion in order to increase the acceptance of medical staff.

(3) SDM should build platform for data using. In the future, we can develop platform for discussing with patients in clinical practice through information systems. With the use of big data, evidence-based data can be used as a reference for treatment.

\section{References}

Angela, C. A. C. (2014). Making shared decision making a reality. London: The King's Fund. 
Chan, Y. H., See, L. C., Tu, H. T., Yeh, Y. H., Chang, S. H., Wu, L. S., ... Kuo, C. T. (2018). Efficacy and Safety of Apixaban, Dabigatran, Rivaroxaban, and Warfarin in Asians With Nonvalvular Atrial Fibrillation. J Am Heart Assoc, 7(8). http://doi.org/10.1161/jaha.117.008150

Chang, T. T., Chen, Y. C., \& Kuo, S. C. (2019). Applying a Patient Decision Aid to Facilitate Decision Making in Women with Pelvic Organ Prolapse. VGH Nursing, 36(4), 353-360. http://doi.org/10.6142/vghn.201912_36(4).0003

Chao, T. F., Lip, G. Y., Liu, C. J., Tuan, T. C., Chen, S. J., Wang, K. L., ... Chen, S. A. (2016). Validation of a Modified CHA2DS2-VASc score for stroke risk stratification in Asian patients with atrial fibrillation: a nationwide cohort study. Stroke, 47(10), 2462-2469. http://doi.org/10.1161/strokeaha.116.013880

Chiang, C. E., Wu, T. J., Ueng, K. C., Chao, T. F., Chang, K. C., Wang, C. C., ... Chen, S. A. (2016). 2016 Guidelines of the Taiwan Heart Rhythm Society and the Taiwan Society of Cardiology for the management of atrial fibrillation. J Formos Med Assoc, 115(11), 893-952. http://doi.org/10.1016/j.jfma.2016.10.005

Chou, C. Y., Liang, H. W., Sun, P. C., \& Sun, J. S. (2017). The practical experience of introducing shared decision making for patients with coronary artery disease in a medical center. Journal of Healthcare Quality, $7(1), 52-63$.

Hargraves, I. G., Montori, V. M., Brito, J. P., Kunneman, M., Shaw, K., LaVecchia, C., .. Thorsteinsdottir, B. (2019). Purposeful SDM: A problem-based approach to caring for patients with shared decision making. Patient Education and Counseling, 102(10), 1786-1792. http://doi.org/10.1016/j.pec.2019.07.020

January, C. T., Wann, L. S., Alpert, J. S., Calkins, H., Cigarroa, J. E., Cleveland, J. C., Jr., ... Yancy, C. W. (2014). 2014 AHA/ACC/HRS guideline for the management of patients with atrial fibrillation: executive summary: a report of the American College of Cardiology/American Heart Association Task Force on practice guidelines and the Heart Rhythm Society. Circulation, 130(23), 2071-2104. http://doi.org/10.1161/cir.0000000000000040

Joseph-Williams, N., Williams, D., Wood, F., Lloyd, A., Brain, K., Thomas, N., ... Edwards, A. (2019). A descriptive model of shared decision making derived from routine implementation in clinical practice ('Implement-SDM'): Qualitative study. Patient Educ Couns, 102(10), 1774-1785. http://doi.org/10.1016/j.pec.2019.07.016

Ryan, P., \& Vaughan, D. (2014). Confronting evidence: individualised care and the case for shared decision-making. Ir Med J, 107(10), 331-332.

Shen, K. F., Chao, C. L., \& Chen, Y. C. (2019). Using Medical Disease Shared Decision-Making to Improve Recognition Accuracy of Spinal Compression Fractures. The Kaohsiung Journal of Nursing, 36(2), 28-40. http://doi.org/10.6692/KJN.201908_36(2).0003

Stacey, D., Legare, F., Col, N. F., Bennett, C. L., Barry, M. J., Eden, K. B., .. Wu, J. H. (2014). Decision aids for people facing health treatment or screening decisions. Cochrane Database Syst Rev, 1(1), Cd001431. http://doi.org/10.1002/14651858.CD001431.pub4

Taiwan Heart Rhythm Society. (2020). Information network of atrial fibrillation health of the Medical Association of the Republic of China. Prevention and treatment of atrial fibrillation. Retrieved from http://www.afhealthcare.org.tw/index.php?action=info-in\&cid=4\&pid=5

Tonelli, M. R., \& Sullivan, M. D. (2019). Person-centred shared decision making. Journal of Evaluation in Clinical Practice, 25(6), 1057-1062. http://doi.org/10.1111/jep.13260

Truglio-Londrigan, M., Slyer, J. T., Singleton, J. K., \& Worral, P. (2012). A qualitative systematic review of internal and external influences on shared decision-making in all health care settings. JBI Libr Syst Rev, 10(58), 4633-4646. http://doi.org/10.11124/jbisrir-2012-432

Wang, Y. G. (2016). Sharing Decision Making Policy - PDA implementation in clinical practice. Journal of Healthcare Quality, 10(4), 15-24.

\section{Copyrights}

Copyright for this article is retained by the author(s), with first publication rights granted to the journal.

This is an open-access article distributed under the terms and conditions of the Creative Commons Attribution license (http://creativecommons.org/licenses/by/4.0/). 